\title{
ВMJ Global Health Impact of night travel ban on road traffic crashes and fatalities in Zambia: an interrupted time series analysis
}

\author{
Peter Hangoma (D) , , ${ }^{1,2}$ Kantu Moonga-Mukale $e^{1,4}$
}

To cite: Hangoma $P$, Moonga-Mukale K. Impact of night travel ban on road traffic crashes and fatalities in Zambia: an interrupted time series analysis. BMJ Global Health 2021;6:e005481. doi:10.1136/ bmjgh-2021-005481

Handling editor Soumyadeep Bhaumik

Received 25 February 2021 Accepted 9 November 2021

Check for updates

(C) Author(s) (or their employer(s)) 2021. Re-use permitted under CC BY-NC. No commercial re-use. See rights and permissions. Published by BMJ.

${ }^{1}$ Department of Health Policy and Management, University of Zambia, Lusaka, Zambia

${ }^{2}$ Development Learning Lab,

Chr. Michelsen Institute, Bergen, Norway

${ }^{3}$ Bergen Centre for Ethics and Priority Setting (BCEPS), University of Bergen, Bergen, Norway

${ }^{4}$ School of Health Sciences, Levy Mwanawasa Medical University, Lusaka, Zambia

Correspondence to

Dr Peter Hangoma;

peterhangoma555@gmail.com

\section{ABSTRACT}

Background The burden of road traffic crashes (RTCs) and road traffic fatalities (RTFs) has been increasing in low-income and middle-income countries (LMICS). Most RTCs and RTFs happen at night. Although few countries, including Zambia, have implemented night travel bans, there is no evidence on the extent to which such policies may reduce crashes and fatalities.

Methods We exploit the quasi-experimental set up afforded by the banning of night travel of public service vehicles in Zambia in 2016 and interrupted time series analysis to assess whether the ban had an impact on both levels and trends in RTCs and RTFs. We use annual administrative data for the period 2006-2020, with 10 pre-intervention and 4 post-intervention data points. In an alternative specification, we restrict the analysis to the period 2012-2020 so that the number of data points are the same pre-interventions and post-interventions. We also carry out robustness checks to rule out other possible explanation of the results including COVID-19.

Results The night travel ban was associated with a reduction in the level of RTCs by 4131.3 (annual average RTCs before the policy=17 668) and a reduction in the annual trend in RTCs by 2485.5. These effects were significant at below $1 \%$, and they amount to an overall reduction in RTCs by $24 \%$. The policy was also associated with a $57.5 \%$ reduction in RTFs. In absolute terms, the trend in RTFs reduced by 477.5 (Annual average RTFs before the policy=1124.7), which is significant at below $1 \%$ level. Our results were broadly unchanged in alternative specifications.

Conclusion We conclude that a night travel ban may be an effective way of reducing the burden of RTCs and RTFs in Zambia and other LMICs. However, complementary policies are needed to achieve more gains.

\section{INTRODUCTION}

The burden of road traffic crashes (RTCs) and road traffic fatalities (RTFs) is a major public health problem with forecasts estimating a significant burden of 14.3 deaths per 100000 population by $2030 .{ }^{1}$ RTCs are responsible for nearly 20-50 million injuries each day, killing about 1.35 million people each year. ${ }^{2}$ In the same vein, road traffic injuries (RTIs) are ranked as the eighth leading

\section{Key questions}

What is already known?

- Several public health interventions, for example, improving road infrastructures such as lighting, can be effective in reducing road traffic crashes (RTCs). However, these may be costly to implement.

- RTCs occur mostly at night, but there is limited or no evidence on the effectiveness of a night travel ban on RTCs and road traffic fatalities (RTFs).

What are the new findings?

- Using a quasi-experimental design, we find that banning night travel of public service vehicles significantly reduced RTCs by $24 \%$ and RTFs by $57.5 \%$. However, both RTCs and RTFs remain high.

\section{What do the new findings imply?}

- Implementing night travel bans may be an effective policy to reduce the burden of road traffic injuries and deaths. However, this intervention alone is not enough to substantially reduce RTCs and RTFs.

cause of death for all age groups worldwide and are a leading cause of death for people between 5 and 29 years. $^{2}$ RTIs account for 83 million disability-adjusted life years (DALYs) lost globally placing it among the five leading causes of DALYs lost. ${ }^{2}$ Perhaps more concerning is the fact that more than $90 \%$ of the DALYs lost occur in low-income and middle-income countries (LMICs), and yet these countries only account for $54 \%$ of registered vehicles globally. ${ }^{3}$ Apart from the large health burden, RTCs also lead to large economic costs in terms of lost productivity and survivors of trauma go on to bear large health costs. A recent study has estimated that the global cost of RTIs is US $\$ 518$ billion. ${ }^{4}$ In addition, RTIs cost governments approximately $3 \%$ of gross domestic product.

Several countries have put in place measures to reduce the burden of RTCs. Measures include stricter rules on speed limits, laws on drunk driving, seat belt use and improving road infrastructure. ${ }^{5}$ Improving 
road infrastructure and related aspects such as lighting has been shown to be important for road safety at night. ${ }^{6}$ Others have banned travel in certain places or at certain times for vehicles or users deemed to be high risk. Countries such Kenya and Zambia have instituted night travel bans. Night travel has been associated with increased risk of RTCs in England, ${ }^{7}$ France, ${ }^{8}$ Ethiopia, ${ }^{9}$ China ${ }^{10}$ and Zambia, ${ }^{11}$ among others. There is a rich literature that has looked at the impact of, or how, different policy measures are associated with RTCs. Intervention evaluated include road improvement interventions in LMICs settings, ${ }^{12}$ speed limit enforcement, ${ }^{13}$ penalty point system, where drivers start with a 12 to 10 point licence and points are gradually removed if certain traffic violations are committed, ${ }^{14}$ and visibility aids such as road lighting. ${ }^{15}$ However, there is limited or no evidence on the impact of night travel bans. The closest of evidence is an ex-ante study of the proposed policy to ban express buses from travelling in the early hours in Malaysia, ${ }^{16}$ but this study was assessing likely impact and not actual impact. Since night travel ban is a form of lockdown, our study may collaborate other studies that have investigated the effect of COVID-19 lockdowns on road injuries. ${ }^{17-19}$ Nonetheless, access to pre-COVID-19 data allows us to investigate the impact of an actual interventions for road injuries and not the indirect effect of economy-wide interventions such as COVID-19 lockdowns. Thus, our study contributes to filling the gap in the literature examining the impact of policies to reduce RTCs in general by examining the impact of a night travel ban in Zambia.

Over the past 50 years, Zambia has witnessed a transformation in the transport system because of both political and economic changes that liberalised the transport sector.Public service vehicles such as buses remain a principal mode of transport for people and account for most of the traffic-related fatalities. According to both historical and current studies, most crashes in Zambia occur during the night. ${ }^{112021}$ Road traffic injuries are the third leading cause of deaths among people aged 15-49 years ${ }^{22}$ higher than causes such as malaria, which also remains a challenge. ${ }^{23}$ Studies also show that injuries are associated with reduced earned income and lower consumption in Zambia. ${ }^{24}$ To curb the increasing number of crashes at night, Zambia instituted a ban on night travel for all public service vehicles in November 2016. According to the statutory instrument, night travel was defined as using a public service vehicle between 21:00 and 05:00. Night travel can thus be viewed as travelling at times when somebody would reasonably be assumed to be sleeping or resting such that their judgement on the road may be impaired compounded by poor visibility during these hours.

\section{METHODS \\ Design}

Our study adopted a quasi-experimental design, particularly a single group interrupted time series analysis
(ITSA). ITSA is a type of study where a time trend is divided or interrupted by an intervention, leading to a pre-intervention period and a post-intervention period. The two time periods are compared to come up with a conclusion on the effects of the intervention. We analysed secondary data on the number of RTCs and RTFs recorded annually, between 2006 and 2020 from the Road Transport and Safety Agency (RTSA). The study population included all the RTCs reported and recorded throughout the country in the study period. We also conducted robustness checks to ensure that the data met the assumptions of ITSA.

\section{Data and variables}

The data consist of annual observations from the year 2006 to 2020. In this period, there were no structural reforms in the transport sector, which were a factor in the 1990s and early 2000s. We restricted our analysis to the period after 2005 to ensure that the data follow the same trend. This is important because ITSA is only valid if the trend is the same in the period. ${ }^{25}$ We however used data on RTCs from 1964 to 2020 in a robustness check and included structural dummies to check if results would be different. Another important issue with including 2020 data is that the number of crashes could have been affected by COVID-19 restrictions. However, Zambia, unlike other countries, did not introduce widespread restrictions such as bans in movements and curfews as was the case in other countries.

Our main outcomes of interest are the annual numbers of RTCs and RTFs in Zambia. RTCs are the number of crashes reported to have occurred in a year and recorded by the Zambia police service and the RTSA. On the other hand, RTFs are the number of crashes that resulted in at least a death. Data on RTCs and RTFs which are disegregated by night and day time would have been ideal to create an intervention (night crashes) and control (day crashes) group, but the statistics were not available in this form. The treatment variable of interest is a binary variable that takes on two values corresponding to the period before the introduction of the travel ban (2006-2016 prior to the policy pronouncement in November 2016) and after (2017-2020). Since the ban was introduced in November 2016 and we only have annual data, the postintervention period was counted from 2017. With this, the number of crashes in 2016 may be lower than they could have been if there was an immediate fall in crashes in December 2016.

The EPOC Cochrane recommends at least three time points per period (before and after the intervention), with equal data points before and after the intervention. However, the biggest issue in ITSA is striking a balance between power and restricting to a period where trends are the same. ${ }^{25}$ It has been shown that one may need many more time points for sufficient power than recommended by EPOC Cochrane. ${ }^{26}$ Thus, in our study, we estimated the model first with 10 pre-intervention periods (2006-2015) and four post-intervention points 
(2017-2020) and then again with equal number of pre-intervention and post-intervention data points. In this case, we had four pre-intervention data points (2012-2015) and four postintervention data points (2017-2020).

We also included other covariates such as motor vehicle population and human population in an alternative specification to check if the results would change given that these variables may be confounders. The variable motor vehicle population is the total number of vehicles registered with the road transport and safety agency in a year. Human population included the total number of people recorded in Zambia each year. The design was aimed at showing whether there was an interruption in the trend after the night travel ban.

\section{Empirical model}

To investigate the effect of the night travel ban on the number of RTCs and RTFs, for both the whole period (2006-2020) and the restricted period (2012-2020), we began with an interrupted time series model of the form:

$$
\begin{aligned}
R T_{t}= & \beta_{0}+\beta_{1} \text { Trends }+\beta_{2} \text { Night_Ban }_{t^{+}} \\
& \beta_{3} \text { Night_Ban } X \text { X Trend }+\mu t
\end{aligned}
$$

Where $\mathrm{RT}_{\mathrm{t}}$ is the number of RTCs or RTFs in year $t$. Trend is the time trend equal to 1 in the first year, 2 in the second year and so on counting the number of years from 2006 to 2020. It controls for trends. Night_Ban is a dummy variable equal to 1 in the period after the night travel ban (postintervention period) and 0 in the preintervention period. It captures the intervention. Night_ Ban $_{t} X$ Trend is the interaction between the night travel ban and RTCs over time. $\mu$ is the error term capturing all other factors that may affect RTCs. $\beta_{0}$ represents the starting level of RTCs in 2006. $\beta_{1}$ is the trajectory of RTCs from the starting level in 2006 until the time that the night travel ban was effected in 2016. The parameter $\beta_{2}$ represents the change in the level of RTCs that occurred in the period immediately following the introduction of the night travel ban compared with the counterfactual. The counterfactual in this case is the predicted slope of progression of RTCs through 2017-2020, had the intervention not been put in place in 2016. $\beta_{3}$ describes the difference between the preintervention slope and the postintervention slope of RTCs. The parameters of interest in our study are $\beta_{3}$.

The model was further modified to add a vector $Z t$ with variables that included the number of motor vehicles recorded and human population (number of people).

$$
\begin{aligned}
R T_{t}= & \beta_{0}+\beta_{1} \text { Trend }+\beta_{2} \text { Night_Ban } t^{+} \\
& \beta_{3} \text { Night_Bant X Trend }+\beta_{4} Z_{t}+\mu_{t}
\end{aligned}
$$

Finally, we carried out diagnostic tests to ensure that the model meet the assumptions relating to normality, homoscedasticity and autocorrelation. Autocorrelation was found, and thus, we allowed an autoregression structure for $\mu_{t}$.

\section{Intervention effect in relative terms}

Both level and slope effects in model 2 can combined to show the combined effect of the policy on road traffic crashes and injuries. This is achieved by comparing the level of RTC or RTI at different points after the intervention to the counterfactual or what they could have been had the policy not been implemented based on model $2{ }^{27}$ To compute the total impact, $\tau_{t}$, of the policy in year $\mathrm{t}$ after the policy, we use the formula:

$$
\tau_{t}=\left(\frac{\hat{R} T_{t(\text { with policy) }}-\hat{R} T_{t(\text { without policy) }}}{\hat{R} T_{t(\text { without policy) }}}\right) \times 100
$$

where $\hat{R} T_{t(\text { without policy) }}=\hat{\beta}_{o}+\hat{\beta}_{1} T+\hat{\beta}_{4} \hat{Z}_{t}$ and

$$
\hat{R} T_{t(\text { with policy })}=\hat{\beta}_{0}+\hat{\beta}_{1} * T+\hat{\beta}_{2} * 1+\hat{\beta}_{3} * T_{\text {post }}+\hat{\beta}_{4} \hat{Z}_{t}
$$

$\hat{R} T_{t}$ is the predicted outcome, $\hat{\beta}_{0}, \hat{\beta}_{1}, \hat{\beta}_{2}, \hat{\beta}_{3}$ and $\hat{\beta}_{4}$ are fitted coefficient from model 2 and $\hat{Z} t$ are the average values of the control variables evaluated at their means. While $T$ is the value of in the $\mathrm{t}^{\text {th }}$ year, $\mathrm{T}_{\text {post }}$ is a count variable of the number of years after the intervention year so that $\mathrm{T}_{\text {post }}=1,2,3$ or 4 and $\mathrm{T}=1,2,3,4,5,6,7,8,9,10,11$, 12 or 13. Thus, the total impact of the night travel ban policy can be expressed as:

$$
\tau_{t}=\left(\frac{\hat{\beta}_{1} T+\hat{\beta}_{2} * 1+\hat{\beta}_{3} * T_{\text {post }}}{\hat{\beta}_{0}+\hat{\beta}_{1} T+\hat{\beta}_{4} \hat{Z}_{t}}\right) \times 100
$$

Getting the geometric mean of $\tau_{t}$ for all t years after the policy gives us the total impact of the intervention, that is: $\tau=\left(\prod_{t=1}^{4} \tau_{t}\right)^{1 / 4}$

Results are presented for the entire period (20062020) and the restricted period (2012-2020).

\section{RESULTS}

\section{Trends in RTCs}

The number of RTCs crashes increased from 1964 to the mid-1970s. From the mid-1970s, the number of RTCs started decreasing (figure 1). The period of falling RTCs corresponds with the oil price crisis in the mid-1970s.

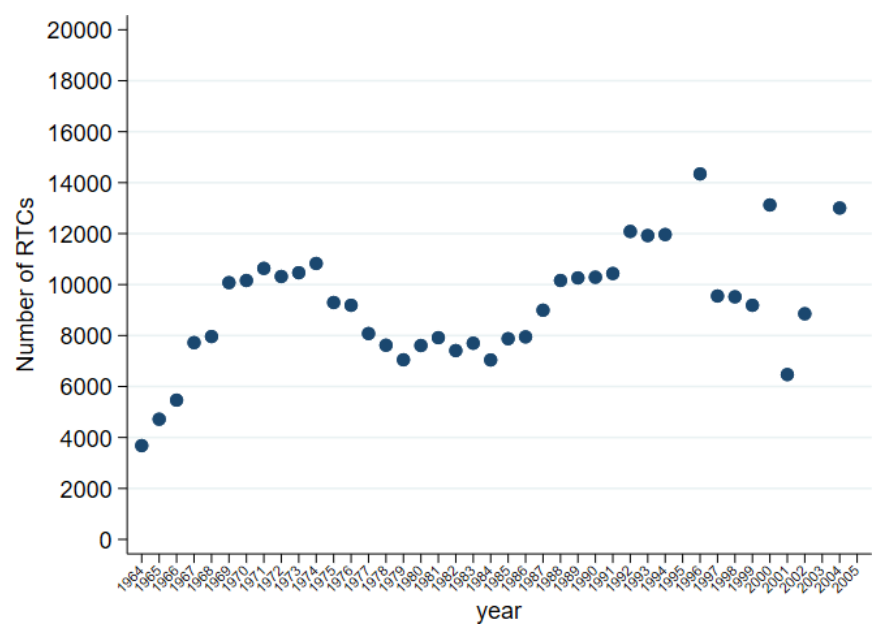

Figure 1 Trends in RTCs in Zambia 1964-2005. RTCs, road traffic crashes. 


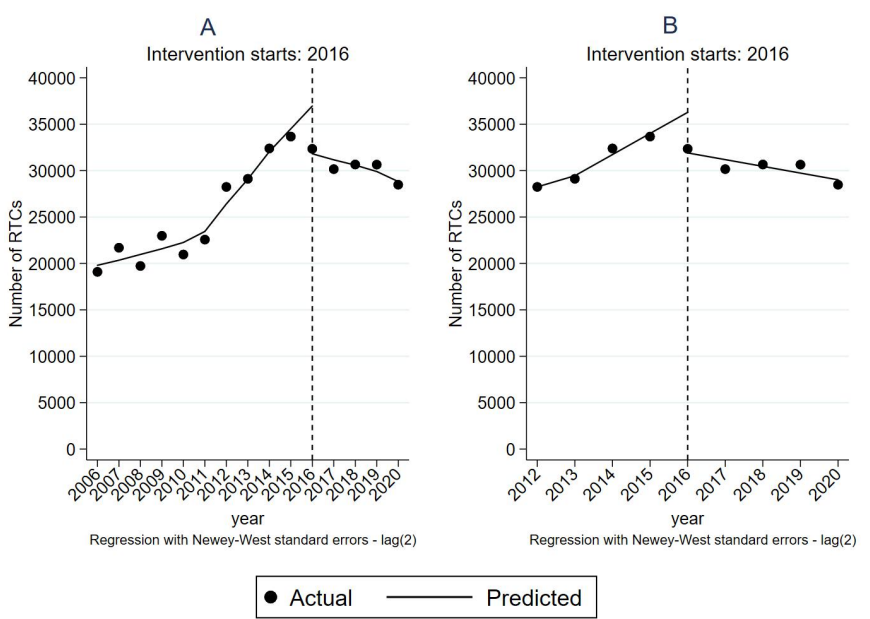

Figure 2 Impact of the night travel ban on road traffic crashes in the whole period $(A)$ and restricted preintervention period (B).

RTCs started rising again in the mid-1980s, starting at around 8000 RTCs in the early to mid-1980s, the number increased to around 12000 in 1992-1993 and then fell again to below 8000 in the early $2000 \mathrm{~s}$. After that number of RTCs were increasing.

\section{The effect of the night travel ban on RTCs in Zambia}

Our results show that the night travel ban significantly reduced RTCs. Beginning with graphical evidence, it can be seen in figure 2 that the number of RTCs was increasing from 2006 until the year of the night travel ban in 2016, and this is clear when one uses the whole period (figure 2A) or 4 years before and 4 years after the ban (figure 2B).

Table 1 shows results of the impact of the night travel ban for the whole period (2006-2020) or when the number of years before and after interventions is the same (the period 2012-2020) based on equation 1. The average number of RTCs in the pre-intervention period (2006-2015) is 17 668.4. The night travel ban was associated with a change in both the level and the yearly trend (slope) in RTCs. The level of RTCs was 4131.3 after the ban compared with what it could have been had there not been a ban (table 1, row 1). In addition, before the policy, RTCs were trending upwards increasing by 1639 each year, implying a positive slope, but after the policy, the annual change in RTCs significantly reduced by 2485.5. Thus, there was a change in trend from annual increases to reductions each year. The combined effect of the level and slope, based on equation 1 , is a reduction in RTCs by $24 \%$. In the restricted period where there is an equal number of years before and after the intervention and the pre-intervention (2012-2020) average annual number of RTCs of 27924.9 , the impact of the policy is broadly the same, though slightly stronger. In this case, the night travel ban is associated with a reduction in the level of RTCs by 4370.7 and a reduction in the trend in RTCs by 3001 , which translates to a $26.7 \%$ reduction in RTCs after the night travel ban.

Table 1 (A) Effect of the night travel ban on road crashes in Zambia and (B) effect of the night travel ban on road crashes and fatalities in Zambia, with and without including year 2020

(A) Effect of the night travel ban on road crashes in Zambia

\begin{tabular}{|c|c|c|c|c|c|c|}
\hline \multirow[b]{2}{*}{ Period (n) } & \multirow[b]{2}{*}{$\begin{array}{l}\text { Preintervention } \\
\text { annual average } \\
\text { RTCs }\end{array}$} & \multicolumn{2}{|c|}{$\begin{array}{l}\text { Level change }\left(\beta_{2}\right) \\
\text { Intervention year==2016 }\end{array}$} & \multicolumn{2}{|c|}{$\begin{array}{l}\text { Slope (trend) change }\left(B_{3}\right) \\
\text { Intervention year==2016 }\end{array}$} & \multirow{2}{*}{$\begin{array}{l}\begin{array}{l}\text { Overall } \\
\text { impact }\end{array} \\
\% \text { change in } \\
\text { RTC }(\tau)\end{array}$} \\
\hline & & $\begin{array}{l}\text { Estimated } \\
\text { change in levels } \\
\text { of RTCs }\end{array}$ & $95 \% \mathrm{Cl}$ & $\begin{array}{l}\text { Estimated change } \\
\text { of trends in RTCs }\end{array}$ & $95 \% \mathrm{Cl}$ & \\
\hline 2006-2020 & 17668.4 & $-4131.3^{\star *}$ & -7680.1 to -582.5 & $-2485.5^{\star \star \star}$ & -4250.9 to -720.0 & -24.0 \\
\hline 2012-2020 & 27924.9 & $-4370.7^{\star \star \star}$ & -6467.3 to -2274.1 & $-3001.7^{\star \star \star}$ & -3911.4 to-2091.9 & -26.7 \\
\hline
\end{tabular}

(B) Effect of the night travel ban on road crashes and fatalities in Zambia, with and without including year 2020

\begin{tabular}{|c|c|c|c|c|c|}
\hline \multirow[b]{2}{*}{ Period (n) } & \multirow[b]{2}{*}{$\begin{array}{l}\text { Preintervention } \\
\text { annual average }\end{array}$} & \multicolumn{2}{|c|}{$\begin{array}{l}\text { Level change }\left(B_{2}\right) \\
\text { Intervention year==2016 }\end{array}$} & \multicolumn{2}{|c|}{$\begin{array}{l}\text { Slope (trend) change }\left(\beta_{3}\right) \\
\text { Intervention year==2016 }\end{array}$} \\
\hline & & $\begin{array}{l}\text { Estimated } \\
\text { change in levels }\end{array}$ & $95 \% \mathrm{Cl}$ & $\begin{array}{l}\text { Estimated change } \\
\text { of trends }\end{array}$ & $95 \% \mathrm{Cl}$ \\
\hline \multicolumn{6}{|l|}{ RTCs } \\
\hline 2006-2019 & 17668.4 & $-4378.741^{\star *}$ & 8434.8 to -322.6 & $-2370.46^{\star \star}$ & -4088.1 to -652.8 \\
\hline $2006-2020$ & 17668.4 & $-4131.3^{\star *}$ & -7680.1 to -582.5 & $-2485.5^{\star \star *}$ & -4250.9 to -720.0 \\
\hline \multicolumn{6}{|l|}{ RTFs } \\
\hline 2006-2019 & 1809.7 & $-408.7^{*}$ & -1384.181 to -0.66 & $-484.96^{\star \star}$ & -283.8 to -197.6 \\
\hline 2006-2020 & 1809.7 & $-521.2^{\star \star}$ & -1002.8 to -39.5 & $-608.7^{\star \star}$ & -1014.9 to -202.5 \\
\hline
\end{tabular}

*ITSA model Newey-West SEs. Models include time-varying covariates such as motor vehicle population and human population.

${ }^{* * *}$ Significant at below $1 \%,{ }^{* *}$ Significant at between $1 \%$ and $5 \%,{ }^{* *}$ Significant at between $5 \%$ and $10 \%$

ITSA, interrupted time series analysis; RTCs, road traffic crashes; RTFs, road traffic fatalities. 


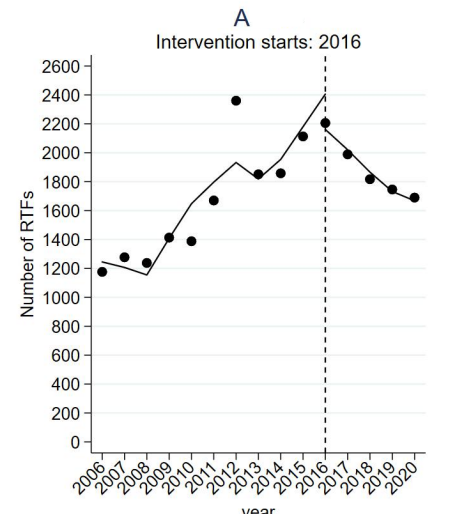

Regression with Newey-West standard errors - $\operatorname{lag}(2)$

- Actual Predicted

Figure 3 Impact of the night travel ban on road traffic fatalities in the whole period $(A)$ and restricted preintervention period (B).

\section{The effect of the night travel ban on fatalities in Zambia}

The night travel ban was also associated with a significant reduction in RTFs. Like RTCs, data show that RTFs were increasing from 2006 until the year of the night travel ban in 2016, seen from both the whole period (figure 3A) or 4 years before and 4 years after the ban (figure 3B).

Overall, the night travel ban of public transport was associated with a $57.5 \%$ reduction in RTFs for the period $2006-2020$ or $68.9 \%$ if the analysis is restricted for the period 2012-2020 (table 2). Beginning with period 2006-2020, the period annual average number of RTFs was 1124.7 road fatalities, and the policy was associated with the reduction in the annual trend in RTFs (slope) by 447.5. In addition, the level of RTFs reduced by 424.8 , but this was not statistically significant at conventional levels. With a restricted pre-intervention period, there was a statistically significant reduction in RTFs both in levels and trends, with magnitudes slightly large than for the full period 2006-2020.

\section{Robustness checks}

Are the results being explained by COVID-19?

Our main analysis includes the 2020 data point. As we have indicated earlier, unlike in many other countries where COVID-19 restrictions included restrictions in movement and night curfews and other, no such policies were implemented in Zambia. It is true, however, that the overall level of activity and travel may have been affected by the COVID-19 restriction in Zambia in 2020 . To assess the extent to which this could be true, we fitted the models omitting the year 2020 and compared the results when the estimation is restricted to 2006-2019 and when the whole period is used. Results show that estimating the model without 2020 does not change the estimated impact, both in levels and slope, of the 2016 night travel ban on RCTs. This also implies that there is no evidence that RCTs reduced further in Zambia due to any COVID-19 lockdown.

However, the reductions in RTFs are slightly stronger when 2020 is included than when the model is estimated up to 2019. This suggest that, although the COVID-19 was not associated with further reductions in RTCs, it was associated with slight reductions in RTFs.

\section{Other robustness checks}

We carried out a few other robustness checks to see whether our model meets standard tests and whether results would change if some other things were accounted for. First, as we have seen from figure 2, the trends would be different if we estimated the model from 1964 to 2019 because of the various changes in the economy that affects this trend. We estimated the model for the whole period and included dummies to account for structural breaks in the years that show different trends, and our results remained unaffected. Specifically, the night travel ban of public transport is still associated with a reduction in RTCs even if the preintervention period is from 1964 to 2020. Second, we ran the models without possible confounders such as annual number of vehicles and population. If the results drastically change with the inclusion of possible confounders, there could be possibilities that the findings are being driven by other unobserved time-varying confounders and not the policy. This did not change the results (online supplemental tables 1 and 2). Third, there could be concern that the classical time series assumption that allow valid inference and estimation may have been violated. In this vein, we tested for normality, homoscedasticity and autocorrelation. In the postestimation, the residuals showed a normal distribution (skewness and kurtosis tests). The residuals had characteristics of heteroscedasticity (8b), and we corrected this by carrying out the analysis using the robust SE. We also identified autocorrelation (Durbin-Watson statistics,

Table 2 Effect of the night travel ban on road fatalities in Zambia

\begin{tabular}{|c|c|c|c|c|c|c|}
\hline \multirow[b]{2}{*}{ Period (n) } & \multirow[b]{2}{*}{$\begin{array}{l}\text { Preintervention annual } \\
\text { average RTFs }\end{array}$} & \multicolumn{2}{|c|}{$\begin{array}{l}\text { Level change }\left(B_{2}\right) \\
\text { Intervention year==2016 }\end{array}$} & \multicolumn{2}{|c|}{$\begin{array}{l}\text { Slope (trend) change }\left(B_{3}\right) \\
\text { Intervention year }==2016\end{array}$} & \multirow{2}{*}{$\begin{array}{l}\begin{array}{l}\text { Overall } \\
\text { impact }\end{array} \\
\% \text { change in } \\
\text { RTC }(\tau)\end{array}$} \\
\hline & & $\begin{array}{l}\text { Estimated change } \\
\text { in levels of RTFs }\end{array}$ & $95 \% \mathrm{Cl}$ & $\begin{array}{l}\text { Estimated change } \\
\text { of trends in RTFs }\end{array}$ & $95 \% \mathrm{Cl}$ & \\
\hline 2006-2020 & 1124.7 & -424.8 & -1042.7 to 193.2 & $-477.5^{\star \star \star}$ & -816.3 to -138.6 & -57.5 \\
\hline 2012-2020 & 1809.7 & $-521.2^{\star \star}$ & -1002.8 to -39.5 & $-608.7^{\star \star}$ & -1014.9 to -202.5 & -68.9 \\
\hline
\end{tabular}

${ }^{*}$ ITSA model Newey-West SEs. Models includes time-varying covariates such as motor vehicle population and human population. ${ }^{* \star}$ Significant at below $1 \%$, ${ }^{* *}$ Significant at between $1 \%$ and $5 \%,{ }^{* *}$ Significant at between $5 \%$ and $10 \%$

ITSA, interrupted time series analysis; RTCs, road traffic crashes; RTFs, road traffic fatalities. 
Breush-Godfrey test). This was corrected by transforming the Durbin-Watson statistic. The analysis was finally carried out with all these corrections and the results of the analysis still showed a significant reduction in RTCs.

\section{DISCUSSION}

This study provides evidence on the impact of banning nighttime travel of public service vehicles on RTCs and RTFs. To the best of our knowledge, this is the first study providing evidence with respect to effect of nigh travel ban of public service vehicles, although such measures are common in other countries. The only other study on a similar topic was a qualitative study on the likely effects of a proposed ban on express bus driving in the early hours in Malaysia.The found that the policy will likely have unintended effects like travellers rushing (overspeeding due to restricted driving hours, potentially increasing risk of RTCs). Our findings, however, show that such a policy may not lead to increases in crashes but instead reduc number of crashes. Our findings show that a night travel ban reduced both the level and trend in the number of crashes and fatalities.

In Africa, Kenya banned night travel for public service vehicle to prevent accidents in 2017. ${ }^{28}$ Although the objective of the ban was to prevent accidents, no evaluation of the restriction on night travel for bus operators has been conducted. Using the opportunity of a quasiexperimental design provided by the public service night travel ban in Zambia in 2016, our results show that the ban significantly reduced RTCs and RTFs. In terms of mechanisms that explain why night travel ban may reduce crashes, it has been documented that that night travel is associated with stress, fatigue, and sleepiness, all

which increase drivers'accident risk. ${ }^{29}$ In Zambia, public service buses are normally driven by the same driver from morning to the end of the day. It is therefore expected that they would be tired and sleepy in the night, which may contribute to road crashes. This could be compounded by poor visibility and poor road infrastructure.

This study ties well with empirical literature investigating the spillover effects of COVID-19 curfews or travel restriction on road injuries and crashes with other studies finding substantial reduction in crashes, ${ }^{30}$ while others only find modest effects. ${ }^{17}$ However, since there are so many things associated with COVID-19, including changes in overall behaviour of people and altitude towards risk, such changes may not solely be attributable to travel restrictions. Our study focuses on impacts of a policy that is specifically targeted and implemented before the COVID-19 period. Our data also include 2020. As discussed, there were no restriction on transport and travel in Zambia in 2020 that we anticipate could have changed the trajectory of RTCs. We conducted the analysis excluding the year 2020, and the results were unchanged for RTCs but were slightly stronger, though quantitatively similar, for RTFs when 2020 was included.
This may suggest that although the COVID-19 period in Zambia did not lead to increases in the number of crashes, it could have led to a slight reduction if the serious of these crashes.

Although we found some reduction, the annual number of RTCs and RTFs were still very high, indicating the need for complementary policies to reduce crashes. Other studies have shown the effectiveness of improving conditions for people driving at night to reduce the number of RTCs. Some studies have documented that corrective measures on nightime driving such as increasing lighting reduced RTCs. ${ }^{6}$ In Zambia, the problem of infrastructure, particularly street lighting in rural areas where villagers walk in the main road in the late evening, has contributed to nightime crashes involving pedestrians, cyclists and motorists. ${ }^{31}$ Clearly, a ban on night-time driving would be more effective in reducing RTCs if a more holistic approach is taken. For example, all drivers, not just public service vehicles drivers, could be sensitised about the dangers of nighttime travel.

However, our study is not without limitations. First, data on road traffic crashes may be prone to underreporting as some crashes may not be captured by the police and the road transport and safety agency. We have estimated the model within the reasonable time frame where we do not anticipate many changes in data reporting habits and as long as reporting errors remain the same in this period, the impact is identified. However, if reporting has increased, then we may have underestimated the impact of the policy. It is crucial however to realise that while crashes in general may be subject to more under-reporting, fatalities may not be amenable to the same under-reoporting as any death due to road accident is reported to the police. However, there are concerns that even some deaths from road injuries remain unreported.

Second, a better study designs that include a control group, such as controlled before-after study designs, would have been more compelling. In such a design, daytime travel and by implication crashes and fatalities could have served as control and nighttime travel as intervention since the policy was only implemented for nighttime travel. However, our data look at all crashes and fatalities and does not distinguish daytime and nighttime crashes and fatalities. With this limitation, we were not able to have a control group. It is possible then that without a control group, the observed impact may have been driven by other concurrent factors. However, we could not imagine what these other factors could have caused a sharp change in the trend of crashes from increasing to reducing immediately after the ban on night-time travel for public service vehicles. The crashes were increasing throughout the pretreatment period and only started reducing after the policy, which lends confidence on the possibility that the observed impact could have been druiven by the policy. 


\section{CONCLUSION}

This study uses data from before and after the night-time travel ban on public service to examine the impact of the policy on road traffic crashes and fatalities in Zambia. Using ITSA, we find that the policy significantly reduced the number of crashes and fatalities. We conclude that night-driving restrictions may be an important policy option in global efforts to reduce the burden of road injuries and fatalities in LMICs. However, this policy alone is not enough to substantially reduce crashes, and other policy options should be used at the same time.

Twitter Peter Hangoma @HangomaPeter

Acknowledgements The study benefitted from data collected from the Zambia police service and the road transport and safety agency. We would like to thank the faculty at the school of public health at the University of Zambia for their valuable comments.

Contributors PH: conceptualisation, methodology, formal analysis, writing and supervision. KMM: investigation, resources, data curation, writing, visualisation and guarantor.

Funding The authors have not declared a specific grant for this research from any funding agency in the public, commercial or not-for-profit sectors.

Competing interests None declared.

Patient consent for publication Not applicable.

Ethics approval Approval to carry out this study was given by the University of Zambia Biomedical Research Ethics Committee Federal Assurance No. FWA00000338, IRB00001131 of IORG0000774.

Provenance and peer review Not commissioned; externally peer reviewed.

Data availability statement Data are available on reasonable request. Data is publicly available and can be requested from the the Road Transport and Safety Agency in Zambia.

Supplemental material This content has been supplied by the author(s). It has not been vetted by BMJ Publishing Group Limited (BMJ) and may not have been peer-reviewed. Any opinions or recommendations discussed are solely those of the author(s) and are not endorsed by BMJ. BMJ disclaims all liability and responsibility arising from any reliance placed on the content. Where the content includes any translated material, BMJ does not warrant the accuracy and reliability of the translations (including but not limited to local regulations, clinical guidelines, terminology, drug names and drug dosages), and is not responsible for any error and/or omissions arising from translation and adaptation or otherwise.

Open access This is an open access article distributed in accordance with the Creative Commons Attribution Non Commercial (CC BY-NC 4.0) license, which permits others to distribute, remix, adapt, build upon this work non-commercially, and license their derivative works on different terms, provided the original work is properly cited, appropriate credit is given, any changes made indicated, and the use is non-commercial. See: http://creativecommons.org/licenses/by-nc/4.0/.

ORCID iD

Peter Hangoma http://orcid.org/0000-0002-6573-5628

\section{REFERENCES}

1 Inada $\mathrm{H}$, Li Q, Bachani A, et al. Forecasting global road traffic injury mortality for 2030. Inj Prev 2020;26:339-43.

2 World Health Organization. Global status report on road safety 2018 . summary, 2018.

3 World Health Organization. Global status report on road safety 2015 , 2015.

4 Bachani AM, Peden M, Gururaj G. Road traffic injuries. In: Mock CN Nugent $\mathrm{R}$, Kobusingye $\mathrm{O}$, eds. Injury prevention and environmental health. Washington, DC: The International Bank for Reconstruction and Development / The World Bank (C) 2017 International Bank for Reconstruction and Development / The World Bank, 2017.
5 WHO. A 5-year WHO strategy dor road traffic injury prevention 2001:17.

6 Plainis S, Murray IJ, Pallikaris IG. Road traffic casualties: understanding the night-time death toll. Inj Prev 2006;12:125-38.

7 Horne JA, Reyner LA. Sleep related vehicle accidents. BMJ 1995;310:565-7.

$8 \mathrm{Nabi} \mathrm{H}$, Guéguen $\mathrm{A}$, Chiron $\mathrm{M}$, et al. Awareness of driving while sleepy and road traffic accidents: prospective study in GAZEL cohort. BMJ 2006;333:75.

9 Abegaz T, Berhane Y, Worku A, et al. Effects of excessive speeding and falling asleep while driving on crash injury severity in Ethiopia: a generalized ordered logit model analysis. Accid Anal Prev 2014;71:15-21.

10 Zhao S, ed. Rapid motorization and road traffic accidents in China. China Presented at 11th World Conference on Transport Research. Dalian: Dalian University of Technology, 2007.

11 Ikabongo M. Trends in road traffic deaths among motorists in Lusaka from 2010 to 2013: University of Zambia, 2015.

12 Staton C, Vissoci J, Gong E, et al. Road traffic injury prevention initiatives: a systematic review and metasummary of effectiveness in low and middle income countries. PLoS One 2016;11:e0144971.

13 Grundy C, Steinbach R, Edwards P, et al. Effect of $20 \mathrm{mph}$ traffic speed zones on road injuries in London, 1986-2006: controlled interrupted time series analysis. BMJ 2009;339:b4469.

14 Novoa AM, Pérez K, Santamariña-Rubio E, et al. Impact of the penalty points system on road traffic injuries in Spain: a time-series study. Am J Public Health 2010;100:2220-7.

15 Porchia BR, Baldasseroni A, Dellisanti C, et al. Effectiveness of two interventions in preventing traffic accidents: a systematic review. Ann Ig 2014;26:63-75.

16 Mohamed N, Mohd-Yusoff M-F, Othman I, et al. Fatigue-related crashes involving express buses in Malaysia: will the proposed policy of banning the early-hour operation reduce fatiguerelated crashes and benefit overall road safety? Accid Anal Prev 2012;45(Suppl):45-9.

17 Sedain B, Pant PR. Road traffic injuries in Nepal during COVID-19 lockdown. F1000Res 2021;9:1209.

18 Navsaria PH, Nicol AJ, Parry CDH, et al. The effect of lockdown on intentional and nonintentional injury during the COVID-19 pandemic in Cape town, South Africa: a preliminary report. S Afr Med $J$ 2021:111:110-3.

19 Lin L, Shi F, Li W. Assessing inequality, irregularity, and severity regarding road traffic safety during COVID-19. Sci Rep 2021;11:1-7.

20 Patel NS. Traffic fatalities in Lusaka, Zambia. Med Sci Law 1979;19:61-5.

21 Fisa R, Nakazwe C, Michelo C, et al. Modelling deaths associated with road traffic accidents and other factors on great North road in Zambia between the years 2010 and 2016 using Poisson models. Open Public Health J 2019;12:68-77.

22 IHME. Zambia Deaths by Cause, 15-49 Years [database on the Internet], 2019. Available: https://vizhub.healthdata.org/gbdcompare/

23 Nawa M, Hangoma P, Morse AP, et al. Investigating the upsurge of malaria prevalence in Zambia between 2010 and 2015: a decomposition of determinants. Malar J 2019;18:61.

24 Hangoma P, Aakvik A, Robberstad B. Health shocks and household welfare in Zambia: an assessment of changing risk. $J$ Int Dev 2018;30:790-817.

25 Bernal JL, Cummins S, Gasparrini A. Interrupted time series regression for the evaluation of public health interventions: a tutorial. International Journal of Epidemiology 2016;46:348-55

26 Ewusie JE, Soobiah C, Blondal E, et al. Methods, applications and challenges in the analysis of interrupted time series data: a scoping review. J Multidiscip Healthc 2020;13:411-23.

27 Wagner AK, Soumerai SB, Zhang F, et al. Segmented regression analysis of interrupted time series studies in medication use research. J Clin Pharm Ther 2002;27:299-309.

28 Xinhua. Kenya bans night travel in the wake of fatal accidents, 2017. Available: http://www.xinhuanet.com/english/2017-12/31/c_ 136863315.htm

29 Taylor AH, Dorn L. Stress, fatigue, health, and risk of road traffic accidents among professional drivers: the contribution of physical inactivity. Annu Rev Public Health 2006;27:371-91.

30 Doucette ML, Tucker A, Auguste ME, et al. Initial impact of COVID-19's stay-at-home order on motor vehicle traffic and crash patterns in Connecticut: an interrupted time series analysis. Inj Prev 2021:27:3-9.

31 Schatz J. On the road in Zambia. The Lancet 2008;372:435-6. 